\title{
A theoretical study of thermodynamics and kinetics of nitrosamines: a potential no carrier
}

\author{
Chin-Hung Lai · Pi-Tai Chou
}

Received: 28 August 2007 / Accepted: 5 December 2007 / Published online: 22 December 2007

(C) Springer-Verlag 2007

\begin{abstract}
In this theoretical study, several hybird DFT functionals and MP2 method are used to investigate the properties and the kinetics of a series of nitrosamines. The results show SN or NS transnitrosation reaction to be more favorable via an $\mathrm{S}_{\mathrm{N}}$ 2-like pathway. The stability is predicted to be in the order of $\mathrm{H}_{2} \mathrm{NNO}>$ cis-MeHNNO $>$ trans-MeHNNO > $\mathrm{Me}_{2} \mathrm{NNO}>$ trans-PhHNNO $>$ cis-PhHNNO $>$ cis-MeSNO $>$ $\mathrm{Ph}_{2} \mathrm{NNO}>N$-methylenenitrous amide, in which $\mathrm{Ph}_{2} \mathrm{NNO}$ and $N$-methylenenitrous amide will be potential candidates for the NO donor. For $N$-methylenenitrous amide, which has the strongest $\mathrm{NO}$ donating strength among the titled nitroamines, a nearly perpendicular configuration between $\mathrm{H}_{2} \mathrm{C}=\mathrm{N}$ and $\mathrm{NO}$ can plausibly be rationalized by the fact that lone pair of the nitrogen atom on the fragment $\mathrm{H}_{2} \mathrm{CN}$ must be $\pi$-type, not $\sigma$-type, to form a mesomeric effect with $\pi^{*} \mathrm{~N}-\mathrm{O}$ of the NO group. Using the polarizable continuum model to consider the water solvent effect, all the barriers and endothermicities of the transnitrosation reactions are decreased and the correlated $\% \mathrm{~N}-\mathrm{H}$ and $\% \mathrm{~N}-\mathrm{S}$ are decreased and increased.
\end{abstract}

Keywords DFT $\cdot$ Nitrosamines $\cdot \mathrm{SN}$ transnitrosation reaction $\cdot$ Mesomeric effect

\section{Introduction}

Nitric oxide (NO) is one of the few gaseous signaling molecules that act as key biological messengers. It plays a role

\footnotetext{
C.-H. Lai $(\varangle)$ · P.-T. Chou

Department of Chemistry,

National Taiwan University,

106 Taipei, Taiwan, ROC

e-mail: chinhunglai@ntu.edu.tw

P.-T. Chou

e-mail: chop@ntu.edu.tw
}

in various biological processes. For example, NO inhibits vascular smooth muscle contraction and growth, platelet aggregation and leukocyte adhesion to the endothelium, resulting in vessel homeostasis [1]. A high-salt intake was proved to attenuate NO production in human [2]. However, NO is a free radical possessing an unpaired electron, which is obviously relevant to its high reactivity and must be stored by a carrier molecule that preserves its biological activity [3-5]. So far, $S$-nitrosothiols (RSNO) have been proposed to play a key role in transporting and storing NO within the organism [6-11]. Recently, Bryan et al. proposed that nitrosamines $(-\mathrm{NNO})$, which are present in similar abundance to $S$-nitrosothiols [12], play similar physiological roles to $S$-nitrosothiols in vivo [13]. For example, aromatic $N$-nitrosamines like $N$-nitrosotryptophan derivatives can generate $S$-nitrosothiols [14] and can also act as direct NO donors [13]. However, to our knowledge, their associated properties are less understood than those of RSNOs.

In another approach, computational chemistry seems to offer a reasonable access to investigate the properties of these important compounds. Schlegel et al. calculated the transnitrosation reaction between cis-MeHNNO and MeSH [15]. Very recently, Ohwada et al. have successfully synthesized some aliphatic $N$-nitrosamines and calculated the barriers of nitrogen to sulfur (NS) transnitrosation reactions [16]. In our previous studies, we have applied various theoretical methods to gain detailed insights into the isomerization pathways of RSNO [17]. Based on Bharatam's work and Natural bond orbital analyses [18], we intend to explore whether the high reactivity of $S$-nitrosothiols is due to the strong negative hyperconjugation $\left(n_{\pi} \mathrm{O} \leftrightarrow \sigma^{*} \mathrm{~N}-\mathrm{S}\right)$. In addition, the mesomeric effect of $S$-nitrosothiols does not cause the breakage of the $\mathrm{N}-\mathrm{O}$ bond due to the compensation of columbic attraction between $\mathrm{N}$ and $\mathrm{O}$. To extend our contribution toward other natural NO resources, we herein report 
a theoretical investigation on a series of nitrosamines in an aim to shed light on their structure, thermodynamic properties, and the reactivity toward, e.g. thiol and amine groups. Particular attention is paid to the NO donating strength and the associated reactions such as sulfur to nitrogen (SN) and nitrogen to sulfur (NS) transnitrosations.

\section{Theoretical method}

All calculations are performed with the Gaussian 03 program [19]. The theoretical levels we have chosen are MP2/6-31G* and six hybrid DFT functionals (B3LYP, B3P86, B3PW91, MPW1LYP, MPW1PW91 and MPW1K) with the same basis set [20-23]. The core electron excitations are neglected in our MP2 calculation. All five points of interest, including reactants, reactant complex (ReaCOM), transition state (TS), product complex (ProdCOM), and products along the potential energy surface (PES) of the reactions are carefully examined. All the stationary points are positively identified as equilibrium structures (the numbers of imaginary frequency $(\mathrm{NIMAG}=0)$ ) or transition states (NIMAG $=1)$. For the transition states, motion corresponding to the imaginary frequency is checked visually. To obtain more accurate energetic values, single-point energy calculations are also performed at the $\mathrm{BD}(\mathrm{T}) / 6-311 \mathrm{G} * / / \mathrm{MP} 2 / 6-31 \mathrm{G}^{*}$ [24] level with the addition of MP2-optimized zero-point vibrational energies (designated $\mathrm{BD}(\mathrm{T})$ hereafter). All mentioned energetic values are corrected for zero-point vibrational energies. Moreover, negative hyperconjugation $\left(n_{\pi \mathrm{O}} \leftrightarrow \sigma^{*} \mathrm{~N}-\mathrm{S}\right)$ and the mesomeric effect proposed in the case of RSNO will be applied to investigate their influence on nitrosamines [25]. Polarizable continuum models (PCM), in which the cavity is created via a series of overlapping spheres, is used to consider the solvent effect of water on the SN or NS transnitrosation reactions [26]. The temperature of the aqueous solution is set to body temperature of $310.0 \mathrm{~K}$ to mimic physiological conditions. The most naturally abundant isotopes are chosen for every element.

\section{Results and discussion}

\subsection{The most optimized DFT functional}

It has been well established that transnitrosation occurs between $S$-nitroso compounds and amines [27-29]. As shown in Scheme 1, pathway 1 is assumed to be an $\mathrm{S}_{\mathrm{N}} 2$-like mechanism, in which nitrosamine is formed through the transition state (TS1) by a $S$-nitrosothiol and a nitrogen nucleophile and a proton is transferred from nitrogen to sulfur simultaneously. Alternatively, the reaction pathway 2 is supposed to involve two transition states (TS2 and TS21) which are separated by

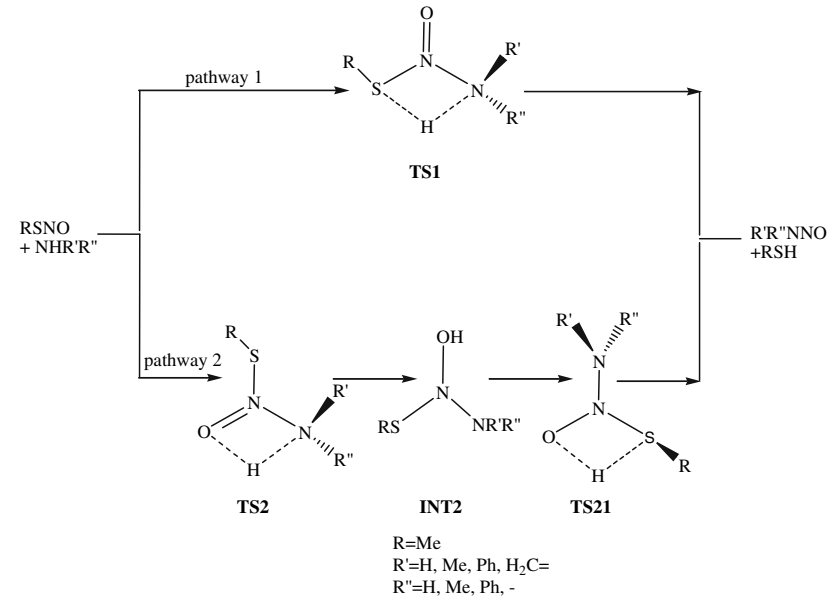

Scheme 1 The proposed mechanism of the SN transnitrosation reaction

an intermediate INT2. Schlegel and coworkers calculated the transnitrosation reaction between cis-MeHNNO and MeSH based on pathway 2 [15]. In another approach, Ohwada and coworkers calculated the transnitrosation reactions between various nitrosamines and $\mathrm{MeSH}$ based upon pathway 1 [16]. In this study, a fair comparison between these two pathways is made. In the first place, we choose cis-MeSNO $+\mathrm{NH}_{3}$ as a model system and apply the proposed pathway 1 with the above-mentioned theoretical methods. Note that in this approach, MeSNO is adopted as a cis conformation, as it has been reported to be more stable than the trans conformation [17]. The results summarized in Table 1 indicate that except for MPW1K, the corresponding transnitrosation is calculated to be endothermic for all applied methods. For example, according to our highest theoretical level, $\mathrm{BD}(\mathrm{T})$, the reaction enthalpy is calculated to be $3.9 \mathrm{kcal} / \mathrm{mol}$ with a barrier height $E_{\mathrm{a}}\left(E_{\mathrm{a}}=E_{\mathrm{TS}}-E_{\text {ReaCOM}}\right.$, see Table 1$)$ of $41.1 \mathrm{kcal} / \mathrm{mol}$. Interestingly, despite its wrongly predicted exothermicity, among the various methods used, the barrier of $38.7 \mathrm{kcal} / \mathrm{mol}$ optimized by the MPW1K method is the closest one to that deduced from $\mathrm{BD}(\mathrm{T})$. Furthermore, a parameter called $D_{\mathrm{dev}}$ is introduced as (Eq. 1) shows to check the relative accuracy of MP2 and all DFT functionals tested with respect to $\mathrm{BD}(\mathrm{T})$

$D_{\mathrm{dev}}=\frac{\left|E_{\mathrm{BD}(\mathrm{T})}-E_{\mathrm{MP} 2}\right|}{\left|E_{\mathrm{BD}(\mathrm{T})}\right|}$

where $E_{\mathrm{BD}(\mathrm{T})}$ and $E_{\mathrm{MP} 2}$ denote the energy of the four interesting points on the potential energy surface, namely ReaCOM, transition state, ProdCOM and product, calculated by $\mathrm{BD}(\mathrm{T})$ and MP2, respectively. We then calculate $D_{\mathrm{dev}}$ of the selected theoretical methods and the results are also listed in Table 1.

Accordingly, the average of $D_{\operatorname{dev}}$ of MP2, B3LYP, B3P86, B3PW91, MPW1LYP, MPW1PW91 and MPW1K are 79.93, $127.1,175.5,138.2,216.5,231.1$ and $353.5 \%$, respectively. 
Table 1 The comparison of various theoretical methods based on the pathway 1 of transnitrosation between $\mathrm{NH}_{3}$ and cis-MeSNO

a The infinitely separated reactants are taken as the energy standard

${ }^{\mathrm{b}} D_{\mathrm{dev}}$ is calculated according to Eq. (1), \langle\rangle denotes the average

\begin{tabular}{lllllc}
\hline & $E_{\text {ReaCOM }}^{\mathrm{a}}$ & $E_{\text {TS1 }}^{\mathrm{a}}$ & $E_{\text {ProdCOM }}^{\mathrm{a}}$ & $E_{\text {products }}^{\mathrm{a}}$ & $\left\langle D_{\text {Dev }}\right\rangle \times 100 \%^{\mathrm{b}}$ \\
\hline MP2 & -3.5 & 34.8 & -1.7 & 3.3 & 79.93 \\
B3LYP & -2.1 & 30.9 & -2.2 & 2.3 & 127.1 \\
B3P86 & -2.0 & 29.1 & -2.9 & 1.5 & 175.5 \\
B3PW91 & -1.5 & 30.7 & -2.2 & 1.4 & 138.2 \\
MPW1LYP & -3.2 & 31.1 & -3.8 & 1.6 & 216.5 \\
MPW1PW91 & -2.3 & 30.8 & -3.8 & 0.6 & 231.1 \\
MPW1K & -2.8 & 35.9 & -6.4 & -2.2 & 393.5 \\
BD(T) & -3.3 & 37.8 & -0.4 & 3.9 & \\
\hline
\end{tabular}

Table 2 The comparison between the pathway 1 and 2 of the transnitrosation reaction cis-MeSNO $+\mathrm{NH}_{3} \rightarrow \mathrm{H}_{2} \mathrm{NNO}+\mathrm{MeSH}$

\begin{tabular}{lllccc}
\hline & $E_{\text {ReaCOM }}^{\mathrm{a}}$ & $E_{\mathrm{TS}}^{\mathrm{a}}$ & $E_{\text {INT }}^{\mathrm{a}}$ & $E_{\mathrm{TS} 1}^{\mathrm{a}}$ & $E_{\text {ProdCOM }}^{\mathrm{a}}$ \\
\hline Pathway 1 & -2.1 & 30.9 & - & 30.9 & -2.2 \\
Pathway 2 & -2.2 & 52.8 & 23.4 & 39.1 & 0.1 \\
\hline
\end{tabular}

${ }^{a}$ The infinitely separated reactants are taken as the energy standard

Accordingly, B3LYP seems to perform the best among all DFT functionals tested for pathway 1. Accordingly, for a fair comparison, thermodynamics along pathway 2 are also calculated on the basis of B3LYP, and the optimized geometries (by B3LYP) of reactant complex (ReaCOM), TS, product complex (ProdCOM), and the nitrosamine product along these two pathways are depicted in Fig. 1. Notably, in this study, since cis-MeSNO may form many stable complexes with respect to nitrogen nucleophiles, we are particularly interested in the reactive complexes that undergo least motion to arrive TS. To do this, we altered the demanding bond lengths of TS and treated it as the initial guess to calculate the reactant complex. On this basis, it is found that there exist different complexes between reaction pathway 1 and 2 . Their corresponding thermodynamics are summarized in Table 2, such that a fair comparison can be made for the two pathways. Evidently, owing to its higher energy barrier, step 1 of pathway 2 (see Scheme 1) should be ascribed to the rate-determining step, the result of which is in agreement with the previous report regarding the reaction between $\mathrm{cis}$ MeSNO and $\mathrm{MeNH}_{2}$ [15]. However, the calculated barrier of $54.9 \mathrm{kcal} / \mathrm{mol}$ is higher in energy than that of pathway 1 by $21.9 \mathrm{kcal} / \mathrm{mol}$. Accordingly, the $\mathrm{SN}$ transnitrosation reaction seems to favor an $\mathrm{S}_{\mathrm{N}}$ 2-like reaction.

\subsection{The substituent effects of methyl groups and phenyl rings on nitrosamines}

The substituent effects of methyl groups and phenyl rings are discussed in this section. The optimized geometries of the titled nitrosamines are depicted in Fig. 2. Additionally,
$\mathrm{N}$-methylenenitrous amide is also considered in this study in order to investigate the differences in the interaction of $\mathrm{sp}^{3}$-nitrogen or $\mathrm{sp}^{2}$-nitrogen with respect to the $\mathrm{NO}$ group. Note that the nitrosamines symbolized as MeHNNO and PhHNNO may exist as a trans or a cis conformer. Both conformers and their respective isomerization TSs are also depicted in Fig. 2. As shown in Fig. 2, the length of the N-N bond is longer in the cis form than it is in the trans form, and it is especially pronounced in PhHNNO. This may be due to the steric hindrance between $\mathrm{Me}$ (or $\mathrm{Ph}$ ) and oxygen atoms, in which the phenyl ring evidently renders a stronger steric effect. In TS, the N-N bond distance is significantly lengthened for both trans and cis forms, while the $\mathrm{N}-\mathrm{O}$ bond distance is conversely shortened. The relative energy, which is defined as $E_{\text {trans }}-E_{c i s}$, is calculated to be 0.5 and $-2.5 \mathrm{kcal} / \mathrm{mol}$ for MeHNNO and PhHNNO, respectively. This may be due to the fact that phenyl ring is much more bulky, such that it induces a strong steric hindrance with the oxygen atom of NO. A similar mechanism can be applied to rationalize why the $\mathrm{N}-\mathrm{N}$ bond distance of $\mathrm{PhHNNO}$ is further lengthened from $1.352 \AA$ in cis-PhHNNO to $1.373 \AA$ in $\mathrm{Ph}_{2} \mathrm{NNO}$. Moreover, the $\mathrm{N}-\mathrm{N}$ bond length is apparently lengthened from $\mathrm{sp}^{3}$-(1.335 $\AA$ ) to $\mathrm{sp}^{2}$-nitrogen $(1.397 \AA)$ attached to the NO group. The barriers of trans $\leftrightarrow$ cis isomerization $\left(E_{\mathrm{TS}}-E_{c i s}\right)$ are calculated to be 25.3 and $19.8 \mathrm{kcal} / \mathrm{mol}$ for MeHNNO and PhHNNO, respectively. In our previous study on $S$-nitrosothiols, it was found that the rotation of $\mathrm{cis}$ MeSNO must overcome a barrier of $14.7 \mathrm{kcal} / \mathrm{mol}$ based on the similar theoretical level [17]. That is to say, cis-MeHNNO must overcome a higher barrier to undergo trans $\leftrightarrow$ cis isomerization than cis-MeSNO must. Furthermore, the critical geometrical parameters of cis-MeSNO and titled nitorsamines are summarized in Table 3 . Table 3 also lists some previous results for a fair comparison [17,30-32]. In agreement with the result of Gauld and coworker, the B3LYP functional seems to lengthen the $\mathrm{N}-\mathrm{S}$ bond of cis-MeSNO if comparing with the QCISD result [32].

Based on Bharatam's work [18], our previous results on $S$-nitrosothiols also concluded that there existed two types of significant orbital interactions in $S$-nitrosothiols [17], namely 
Fig. 1 The optimized geometries of complexes, transition states, intermediate of transnitrosation between cis-MeSNO and $\mathrm{NH}_{3}$ and the product $\mathrm{H}_{2} \mathrm{NN}=\mathrm{O}$ (The bond length in $\AA$, the bond angle in ${ }^{\circ}$, the color of the atom decreases from black to white according to atomic number)

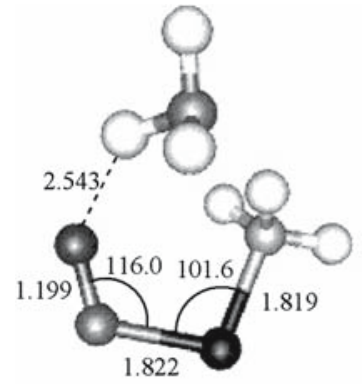

ReaCOM

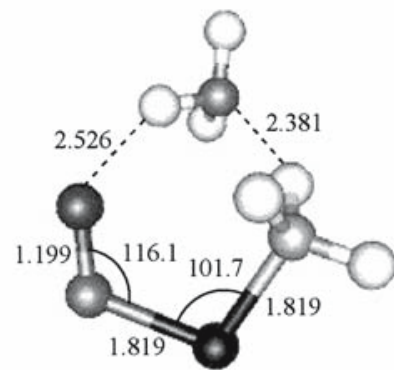

ReaCOM'

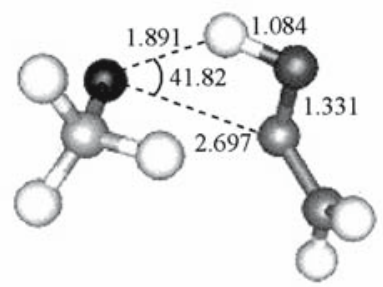

TS1'

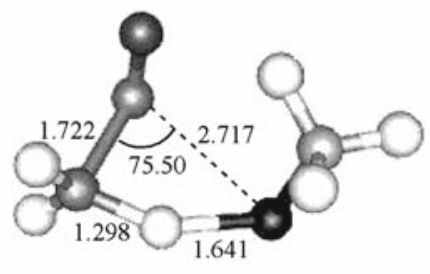

TS

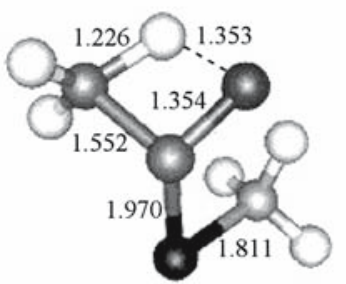

TS'

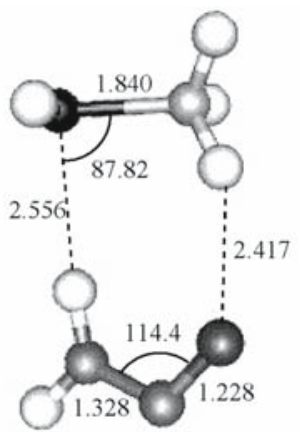

ProdCOM

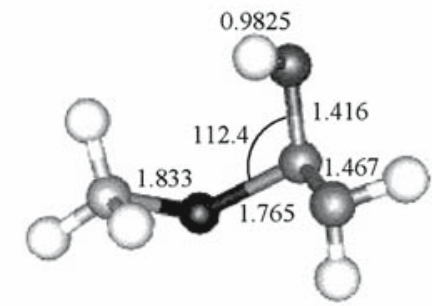

INT

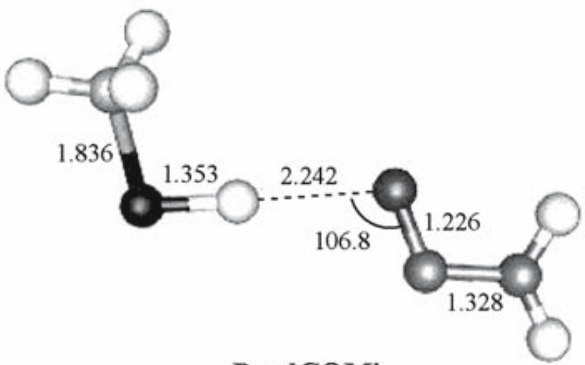

ProdCOM'

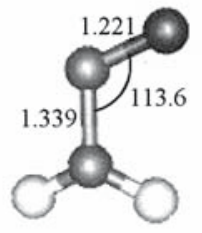

$\mathrm{H}_{2} \mathrm{NN}=\mathbf{O}$ the mesomeric effect $\left(n_{\mathrm{S}} \leftrightarrow \pi^{*}{ }_{\mathrm{N}-\mathrm{O}}\right)$ and the negative hyperconjugation $\left(n_{\pi \mathrm{O}} \leftrightarrow \sigma^{*} \mathrm{~N}-\mathrm{S}\right)$. We have applied the coordination of $\mathrm{BH}_{3}$ or $\mathrm{Cu}^{+}$toward $S$-nitrosothiols to check the effect of each individual interaction on the stability of $S$-nitrosothiols. It was found that the mesomeric effect was compensated by the columbic attraction between $\mathrm{N}$ and $\mathrm{O}$, with the net effect being a stabilizing factor on $S$-nitrosothiols. Conversely, the high reactivity of $S$-nitrosothiol was due to the strong negative hyperconjugation $[17,18]$. The strengths of the corresponding orbital interactions in nitrosamines can thus be extracted by NBO analyses. Taking the mesomeric effect $\left(n_{\mathrm{S}} \leftrightarrow \pi^{*} \mathrm{~N}-\mathrm{O}\right)$ of $S$-nitrosothiols as an example, the interaction strength between $\mathrm{n}_{\mathrm{S}}$ and $\pi^{*} \mathrm{~N}-\mathrm{O}$ should be inversely proportional to the corresponding energy gap. According to the second order perturbation theory, the interaction energy $E^{(2)}$ of the mesomeric effect can be written as (Eq. 1):

$E^{(2)}=2 \frac{\left\langle\left. n_{s}\left|H_{\mathrm{int}}\right| \pi_{\mathrm{N}-\mathrm{O}}^{*}\right|^{2}\right.}{E_{\pi_{\mathrm{N}-\mathrm{O}}^{*}}-E_{n_{\mathrm{s}}}}$

where $\mathrm{E}_{\mathrm{ns}}$ and $\mathrm{E}_{\pi} * \mathrm{~N}-\mathrm{O}$ are the energy of $\mathrm{n}_{\mathrm{S}}$ and $\pi_{\mathrm{N}-\mathrm{O}} *$ orbitals, respectively. $\mathrm{H}_{\text {int }}$ is the interacting Hamiltonian. The number 2 on the right side of (Eq. 2) indicates the number of electrons occupied on the $n_{\mathrm{S}}$ orbital. In Table 4, 
Fig. 2 The optimized geometries of nitrosamines and their isomerized TSs (The bond length in $\AA$, the bond angle in ${ }^{\circ}$, the color of the atom decreases from black to white according to atomic number)

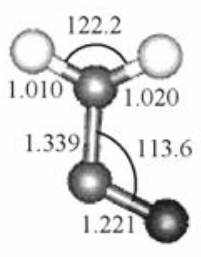

$\mathrm{H}_{2} \mathrm{NNO}$

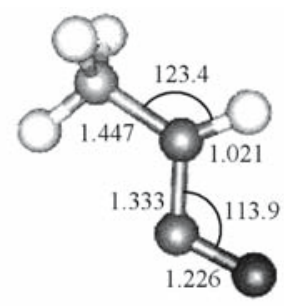

trans-MeHNNO

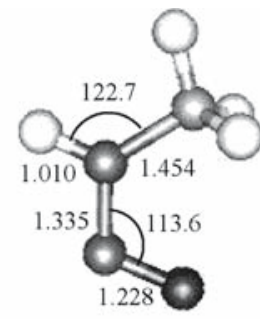

cis-MeHNNO
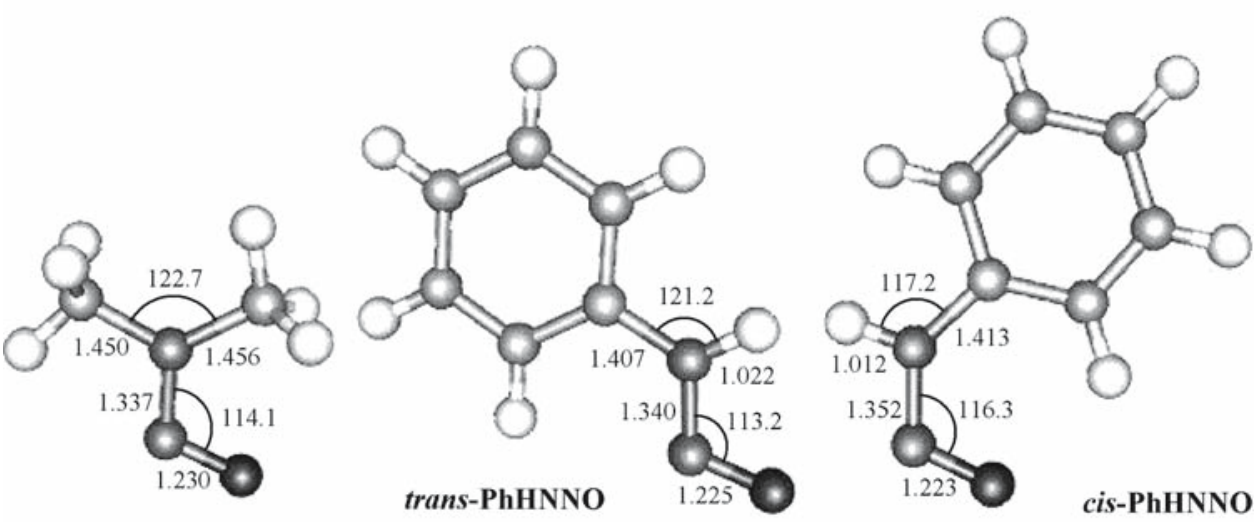

$\mathrm{Me}_{2} \mathrm{NNO}$

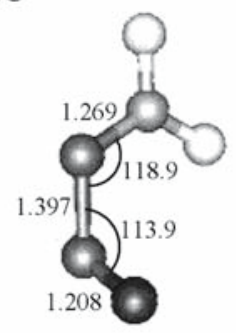

$<\mathrm{C}-\mathrm{N}-\mathrm{N}-\mathrm{O}=84.00$

$\mathrm{N}$-methylenenitrous amide

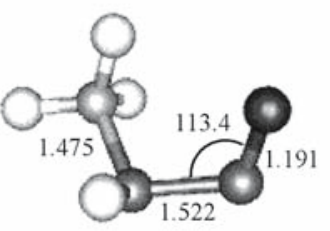

$<\mathrm{C}-\mathrm{N}-\mathrm{N}-\mathrm{O}=52.88$

MeHNNO-TS
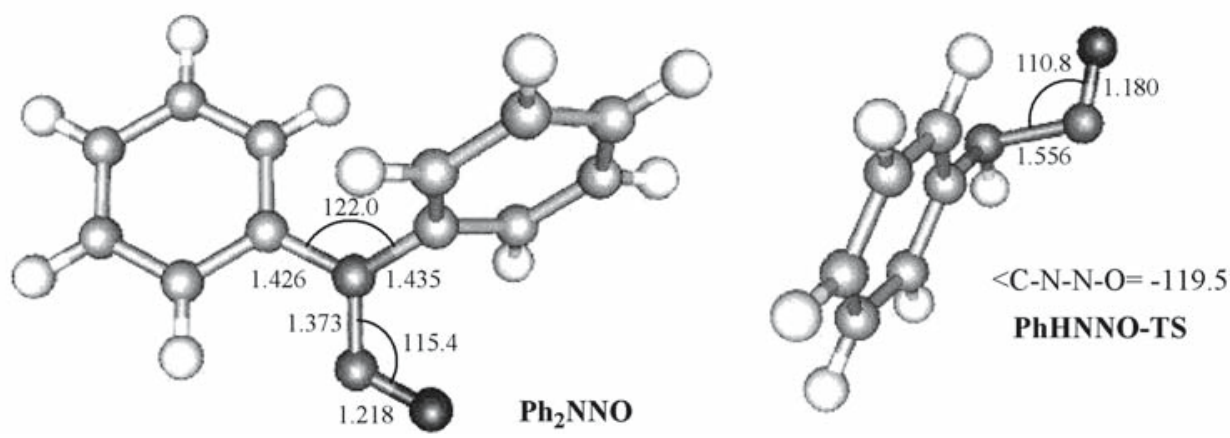

$E^{(2)}$ for mesomeric effect and negative hyperconjugation of cis-MeSNO and nitrosamines are calculated and summarized. As listed in Table 4, all titled nitrosamines, except for $N$-methylenenitrous amide, possess stronger mesomeric effects but weaker negative hyperconjugation than that of cis-MeSNO. However, in addition to these two orbital interactions, other intrinsic properties may influence the stability order of $S$-nitrosothiols and nitrosamines. For example, it has been reported [33] that $3 \mathrm{p}-2 \mathrm{p}$ orbital overlapping in $\mathrm{S}-\mathrm{N}$ (e.g. MeSNO) is worse than that of the $2 \mathrm{p}-2 \mathrm{p}$ orbital in $\mathrm{N}-\mathrm{N}$ (e.g. MeHNNO). It is also worth note that the dihedral angle $<\mathrm{C}-\mathrm{N}-\mathrm{N}-\mathrm{O}$ in e.g. $\mathrm{N}$-methylenenitrous amide is calculated to be $84.00^{\circ}$, indicating that $\mathrm{H}_{2} \mathrm{C}=\mathrm{N}$ is nearly perpendicular to NO. The result may be due to the fact that the lone pair 
Table 3 Optimized bond lengths ( $\AA$ ) and bond angles (o) for cis-MeSNO and titled nitrosamines

\begin{tabular}{llll}
\hline & $r(\mathrm{~N}-\mathrm{O})$ & $\begin{array}{l}r(\mathrm{~N}-\mathrm{X}) \\
\mathrm{X}=\mathrm{S} \text { or N }\end{array}$ & $\begin{array}{l}<(\mathrm{O}-\mathrm{N}-\mathrm{X}) \\
\mathrm{X}=\mathrm{S} \text { or N }\end{array}$ \\
\hline cis-MeSNO & 1.19 & 1.87 & 117 \\
& $1.19^{\mathrm{a}}$ & $1.82^{\mathrm{a}}$ & $117^{\mathrm{a}}$ \\
& $1.18^{\mathrm{b}}$ & $1.86^{\mathrm{b}}$ & $117^{\mathrm{b}}$ \\
& $1.22^{\mathrm{c}}$ & $1.78^{\mathrm{c}}$ & $114^{\mathrm{c}}$ \\
& $1.19^{\mathrm{d}}$ & $1.80^{\mathrm{d}}$ & \\
$\mathrm{H}_{2} \mathrm{NNO}$ & 1.22 & 1.34 & 114 \\
& $1.24^{\mathrm{c}}$ & $1.34^{\mathrm{c}}$ & $113^{\mathrm{c}}$ \\
trans-MeHNNO & 1.23 & 1.33 & 114 \\
cis-MeHNNO & 1.23 & 1.34 & 114 \\
& $1.24^{\mathrm{c}}$ & $1.33^{\mathrm{c}}$ & $113^{\mathrm{c}}$ \\
$\mathrm{Me}_{2} \mathrm{NNO}$ & 1.23 & 1.34 & 114 \\
trans-PhHNNO & 1.23 & 1.34 & 113 \\
& $1.24^{\mathrm{c}}$ & $1.34^{\mathrm{c}}$ & $113^{\mathrm{c}}$ \\
cis-PhHNNO & 1.22 & 1.35 & 116 \\
$\mathrm{Ph}{ }_{2} \mathrm{NNO}$ & 1.22 & $1.37^{2}$ & 115 \\
$N$-methylenenitrous amide & 1.21 & 1.40 & 114
\end{tabular}

a The value is calculated by B3P86/6-31++G**, see [30]

b The value is calculated by B3LYP/6-311+G*, see [30]

${ }^{c}$ The values are obtained by the G3 method, see [31]

$\mathrm{d}$ The values are obtained by the QCISD/6-311+G(2df,p) method, see [32]

of nitrogen atom on the fragment $\mathrm{H}_{2} \mathrm{CN}$ must be a $\pi$-type, not a $\sigma$-type, to induce mesomeric effect with $\pi *{ }_{N}-\mathrm{O}$ of the NO group.

To gain more detailed insight into the overall perturbation, the relative stabilities between these nitrosamines and cis-MeSNO are further investigated by the homolytic bond dissociation energies (BDEs) of the $\mathrm{N}-\mathrm{X}$ bonds $(\mathrm{X}=\mathrm{N}, \mathrm{S})$. Although the $\mathrm{N}-\mathrm{X}$ bond may also undergo heterolytic breakage, it has been proven that the homolytic process is more favorable than the heterolytic one and the biological activity of RSNOs has been mostly attributed to the homolytic cleavage of the $\mathrm{N}-\mathrm{S}$ bond [34-36]. It is reasonable to conclude that the larger the $\mathrm{BDE}$ of the $\mathrm{N}-\mathrm{X}$ bond is, the more stable the molecule is. In this regard, RSNOs are famous NO donors, and their BDEs of the N-S bond are measured to be $20 \sim 28 \mathrm{kcal} / \mathrm{mol}$ experimentally [37]. In our computational approach, the optimized BDE of the N-S bond in cis-MeSNO is estimated to be $28.7 \mathrm{kcal} / \mathrm{mol}$, a value which is close to the experimental value [37]. The BDE of the N-S bond in RSNO was reported to be sensitive to the basis set and underestimated by the B3YP functional [32]. However, as shown in Table 4, the calculated BDEs of N-S and N-N bonds are only deviated from the previous $\mathrm{G} 3$ results by $\sim 1.3 \mathrm{kcal} / \mathrm{mol}$ in average [31]. The G3 method is proved to be able to give highaccuracy thermodynamic data and its overall average absolute deviation from experiment has already deduced to be as
Table 4 Second-order perturbation energy $E^{(2)}$ for mesomeric effect and negative hyperconjugation and corresponding $\mathrm{BDE}$ (all in $\mathrm{kcal} / \mathrm{mol}$ ) of $\mathrm{RXNO}(\mathrm{X}=\mathrm{S}$ or $\mathrm{N})$

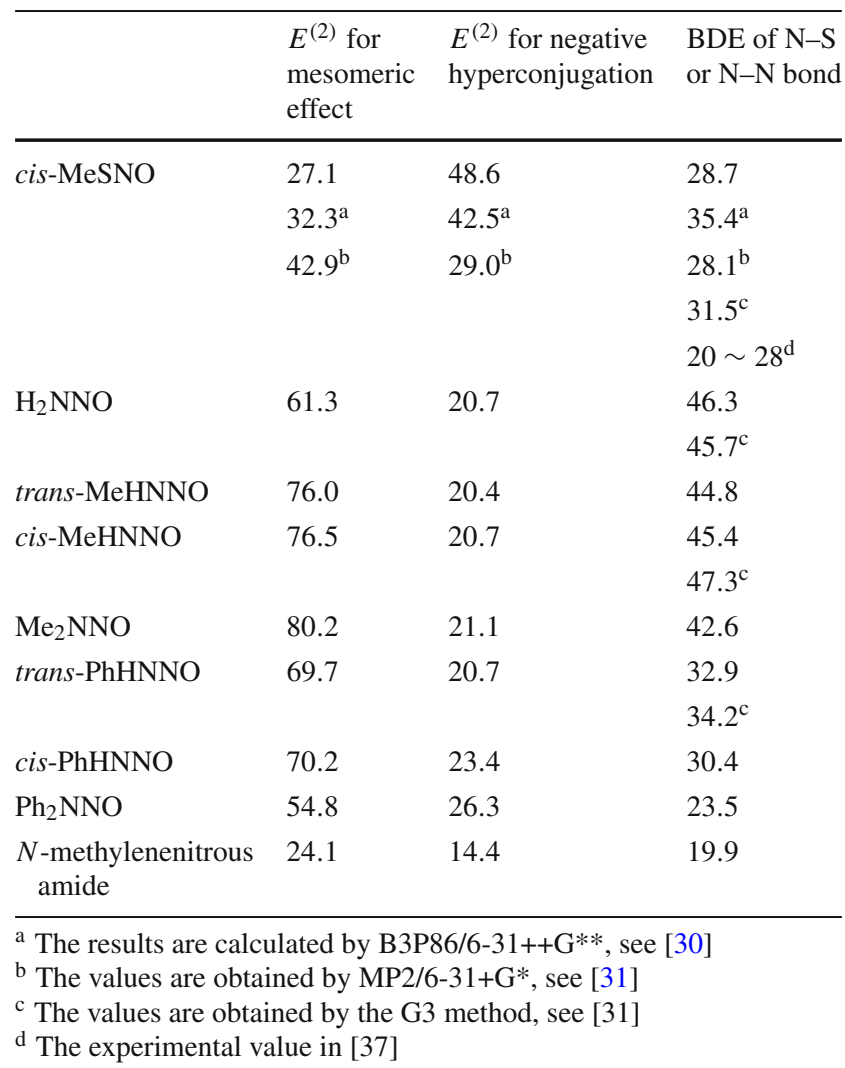

small as $1.02 \mathrm{kcal} / \mathrm{mol}$ [38]. Therefore, the optimized BDEs should be accurate enough to make a fair comparison, at least in a qualitative manner, and the calculated BDEs are summarized in Table 4. As listed in Table 4, the thermal stability is in the order of $\mathrm{H}_{2} \mathrm{NNO}>$ cis-MeHNNO $>$ trans-MeHNNO > $\mathrm{Me}_{2} \mathrm{NNO}>$ trans-PhHNNO $>$ cis-PhHNNO $>$ cis-MeSNO $>$ $\mathrm{Ph}_{2} \mathrm{NNO}>N$-methylenenitrous amide. Obviously, due to their less stability than that of cis-MeSNO, $\mathrm{Ph}_{2} \mathrm{NNO}$ and $\mathrm{N}$-methylenenitrous amide analogues may act as a suitable NO donor. This result provides theoretical evidence in support of the experimental observation that certain aromatic $N$-nitrosamines can act as a direct NO donor [13]. Our results also clearly show that the $\mathrm{N}-\mathrm{N}$ bond in $\mathrm{N}$-methylenenitrous amide is the weakest among all titled nitrosamines, suggesting that $N$-methylenenitrous amide, if synthesis is feasible, may serve as a better NO donor than RSNOs and aromatic nitrosamines.

\subsection{The SN transnitrosation reactions and the reactivity} of a nitrosamine

Based on pathway 1, Table 5 lists the barriers of the SN transnitrosation reactions between cis-MeSNO and corresponding nitrogen nucleophiles to produce the nitrosamines shown in 
Table 5 The barriers, reaction heats, $\% \mathrm{~N}-\mathrm{H}$ and $\% \mathrm{~N}-\mathrm{S}$ of the $\mathrm{SN}$ transnitrosation reactions between cis-MeSNO and different nitrogen nucleophiles

\begin{tabular}{lllccl}
\hline & $E_{\mathrm{a}}^{\mathrm{a}}$ & $E_{\mathrm{a}}^{\prime \mathrm{a}}$ & $\Delta \mathrm{H}$ & $\% \mathrm{~N}-\mathrm{H}^{\mathrm{b}}$ & $\% \mathrm{~N}-\mathrm{S}^{\mathrm{b}}$ \\
\hline $\mathrm{NH}_{3}$ & 33.0 & 33.1 & 2.3 & 27.30 & 45.65 \\
& $24.5^{\mathrm{c}}$ & $28.9^{\mathrm{c}}$ & $-5.6^{\mathrm{c}}$ & $9.87^{\mathrm{c}}$ & $77.56^{\mathrm{c}}$ \\
$\mathrm{MeNH}_{2}$ & 26.8 & 33.1 & -4.2 & 28.86 & 48.61 \\
& $19.1^{\mathrm{c}}$ & $28.0^{\mathrm{c}}$ & $-11.2^{\mathrm{c}}$ & $9.74^{\mathrm{c}}$ & $80.38^{\mathrm{c}}$ \\
$\mathrm{Me}_{2} \mathrm{NH}$ & 23.4 & 30.8 & -7.7 & 28.19 & 51.68 \\
& $19.2^{\mathrm{c}}$ & $29.1^{\mathrm{c}}$ & $-12.4^{\mathrm{c}}$ & $11.26^{\mathrm{c}}$ & $81.01^{\mathrm{c}}$ \\
$\mathrm{PhNH}_{2}$ & 29.9 & 32.7 & -0.1 & 35.25 & 42.53 \\
& $25.6^{\mathrm{c}}$ & $29.5^{\mathrm{c}}$ & $-2.9^{\mathrm{c}}$ & $10.77^{\mathrm{c}}$ & $89.74^{\mathrm{c}}$ \\
$\mathrm{Ph}_{2} \mathrm{NH}$ & 28.0 & 24.7 & 2.8 & 46.01 & 39.43 \\
& $29.2^{\mathrm{c}}$ & $28.9^{\mathrm{c}}$ & $0.3^{\mathrm{c}}$ & $37.12^{\mathrm{c}}$ & $54.99^{\mathrm{c}}$ \\
$\mathrm{H}_{2} \mathrm{C}=\mathrm{NH}$ & 31.3 & 21.6 & 10.0 & 15.64 & 45.47 \\
& $29.5^{\mathrm{c}}$ & $21.2^{\mathrm{c}}$ & $8.9^{\mathrm{c}}$ & $7.32^{\mathrm{c}}$ & $85.63^{\mathrm{c}}$ \\
& & &
\end{tabular}

${ }^{\mathrm{a}} E_{\mathrm{a}}=E_{\mathrm{TS}}-E_{\mathrm{ReaCOM}}, E a^{\prime}=E_{\mathrm{TS}}-E_{\text {ProdCOM }}$, the unit of the energetic value is $\mathrm{kcal} / \mathrm{mol}$

$\mathrm{b}$ The parameters are defined in Eqs. (3) and (4)

${ }^{c}$ The values are obtained as considering the solvent effect of water by full optimization

Fig. 2. Figure 3 depicts the geometries of corresponding ReaCOMs, TSs and ProdCOMs along the potential energy surfaces of the SN transnitrosation reactions. As listed in Table 5, with respect to cis-MeSNO, the $\mathrm{SN}$ transnitrosation reaction of phenylamine is nearly thermoneutral, while the similar reaction of methylamine and dimethylamine is exothermic. We thus conclude that the $\mathrm{SN}$ transnitrosation reactions of ammonia, diphenylamine and methanimine are not thermodynamically favorable, while this reaction is allowed between cis-MeSNO and dimethylamine. In our previous study about the transnitrosation reactions between MeXNO and $\mathrm{YMe}^{-}(\mathrm{X}=\mathrm{S}, \mathrm{Se} ; \mathrm{Y}=\mathrm{S}, \mathrm{Se})$ [39], the reactions are found to undergo concerted reactions in the aqueous solution at $310 \mathrm{~K}$ by fully optimized PCM model. The result is in sharp contrast to the two-step reaction pathways concluded in the gas phase $[39,40]$. Therefore, the $\mathrm{SN}$ transnitrosation reactions are also investigated by fully optimized PCM model to simulate the physiological conditions in this study. For a fair comparison, the results including the solvent effect of water are also listed in Table 5. Clearly, all the barriers and endothermicities of the transnitrosation reactions are decreased in the aqueous solution, implying a more polar TS and product environment with respect to that of the reactants.

Nitrosamines are supposed to deliver NO in either a direct or indirect manner. As for the direct pathway, the $\mathrm{N}-\mathrm{N}$ bond is ruptured intramolecularly to render $\mathrm{NO}^{\circ}$ and $R^{\prime} R^{\prime \prime} \mathrm{N}^{*}$. Alternatively, the indirect pathway incorporates the transnitrosation to generate an unstable $S$-nitrosothiol, which then decomposes to NO and SR $[13,14]$. For the latter case, $\mathrm{Ea}^{\prime}$ in Table 5 can be viewed as the barrier of the nitrogen to sul- fur (NS) transnitrosation reaction. From a kinetic viewpoint, the results show that the reverse NS transnitrosation reaction, except for $\mathrm{Ph}_{2} \mathrm{NNO}$ and $N$-methylenenitrous amide, requires more energy to occur than the forward $\mathrm{SN}$ transnitrosation reaction. This viewpoint is in agreement with the experimental result in that the generation of $S$-nitrosothiols from aromatic $N$-nitrosamines is feasible [14]. The result also predicts that $N$-methylenenitrous amide should more easily undergo the NS transnitrosation reaction than $\mathrm{Ph}_{2} \mathrm{NNO}$. Therefore, $N$-methylenenitrous amide can be considered to be more labile than $\mathrm{Ph}_{2} \mathrm{NNO}$ in both direct and indirect generation of NO.

To gain more insight into the substituent effect of methyl group and phenyl ring on the geometry of TS, we then apply two parameters, $\% \mathrm{~N}-\mathrm{H}$ and $\% \mathrm{~N}-\mathrm{S}$, expressed in (Eqs. 3, 4), to check the degree of the bond breakage of $\mathrm{N}-\mathrm{H}$ and $\mathrm{N}-\mathrm{S}$ in TS

$$
\begin{aligned}
& \% \mathrm{~N}-\mathrm{H}=\frac{r_{\mathrm{N}-\mathrm{H}}(T S)-r_{\mathrm{N}-\mathrm{H}}(\mathrm{N})}{r_{\mathrm{N}-\mathrm{H}}(\mathrm{N})} \\
& \% \mathrm{~N}-\mathrm{S}=\frac{r_{\mathrm{N}-\mathrm{S}}(\mathrm{TS})-r_{\mathrm{N}-\mathrm{S}}(\mathrm{MeSNO})}{r_{\mathrm{N}-\mathrm{S}}(\mathrm{MeSNO})}
\end{aligned}
$$

where $r_{\mathrm{N}-\mathrm{H}}$ (TS) and $r_{\mathrm{N}-\mathrm{S}}$ (TS) indicate the bond lengths of $\mathrm{N}-\mathrm{H}$ and $\mathrm{N}-\mathrm{S}$ in the transition state, and $\mathrm{N}$ represents the mentioned nitrogen nucleophiles. The results shown in Table 5 clearly indicate that $\% \mathrm{~N}-\mathrm{H}$ becomes larger as the hydrogen atom of $\mathrm{NH}_{3}$ is replaced by either a methyl group or phenyl ring. However, the value of $\% \mathrm{~N}-\mathrm{S}$ increases as methyl groups substitute hydrogen and decreases as phenyl rings substitute hydrogen. Upon considering the solvent effect of water, the values of $\% \mathrm{~N}-\mathrm{H}(\% \mathrm{~N}-\mathrm{S})$ are decreased (increased) in all cases. The reactivity of nitrosamine is further investigated by taking $\mathrm{H}_{2} \mathrm{NNO}$ and $\mathrm{NH}_{3}$ as a model system, and the ReaCOM, TS and ProdCOM of this reaction based on pathway 1 are also depicted in Fig. 3. The activation energy of this reaction is calculated to be $50.6 \mathrm{kcal} / \mathrm{mol}$, the results of which indicate that thiols are more efficient nucleophiles than amines upon reacting with nitrosamines.

Based on pathway 2 depicted in Scheme 1, Schlegel and coworkers found one extra water molecule cannot catalyze the NS transnitrosation reaction between cis-MeHNNO and MeSH efficiently [15]. On one hand, in this study, we intended to investigate whether a similar catalytic effect is also unfavorable upon one-water catalysis. On the other hand, it should be interesting to investigate the role of $\mathrm{NH}_{3}$ in the relevant reaction, in which one $\mathrm{NH}_{3}$ was used as the reactant, while the other may be used as a catalyst. Similar dual roles of the reactant have been found in other reaction. For example, Plummer et al. used HF method to calculate the reaction $\mathrm{SO}_{3}+\mathrm{H}_{2} \mathrm{O} \rightarrow \mathrm{H}_{2} \mathrm{SO}_{4}$ and found that a large barrier height existed between adduct and sulfuric acid, the result of which seemed to discount the simple picture of the rapid reaction of sulfur-trioxide with one water molecule to form the acid 

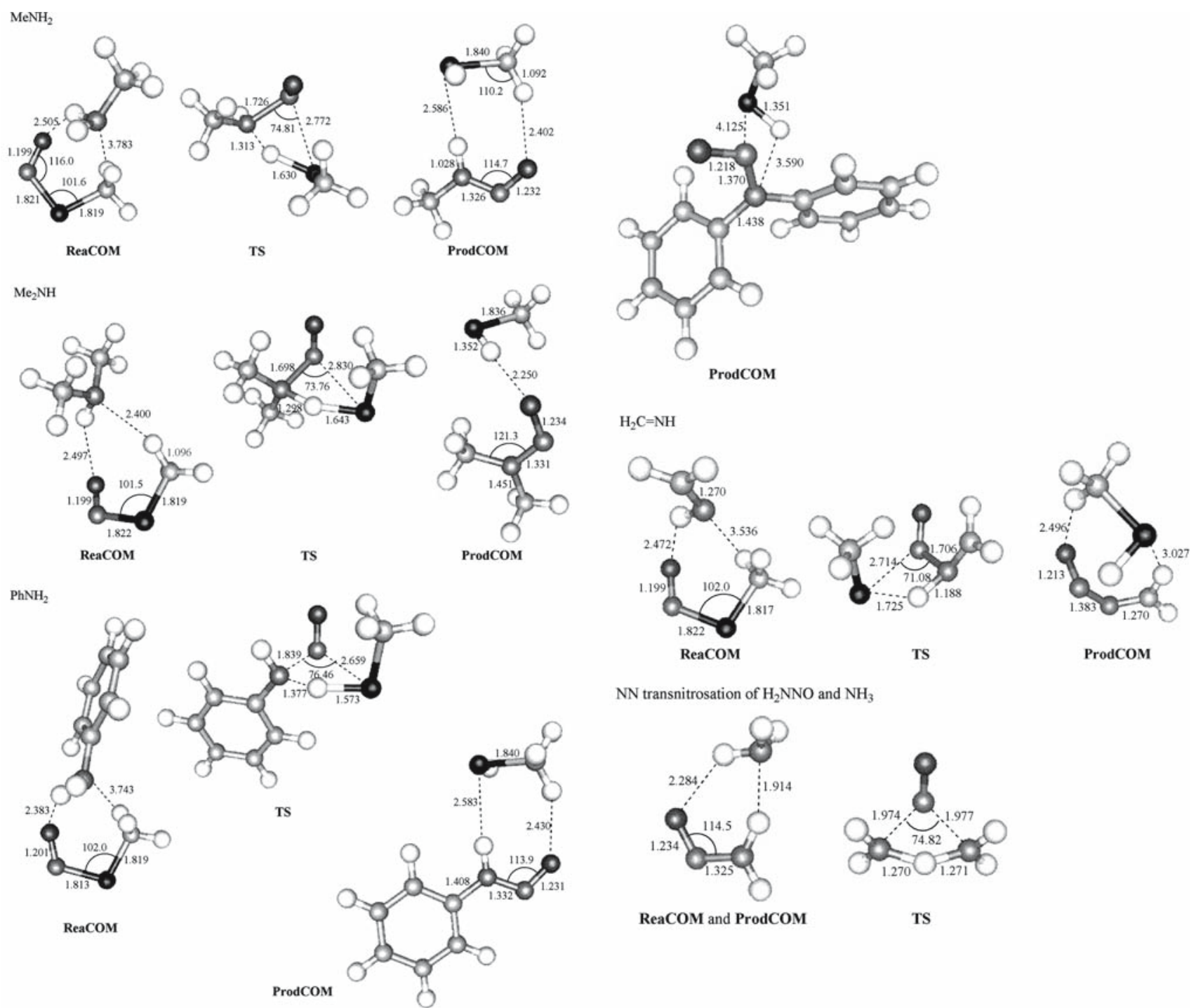

$\mathrm{NN}$ transnitrosation of $\mathrm{H}_{2} \mathrm{NNO}$ and $\mathrm{NH}_{3}$

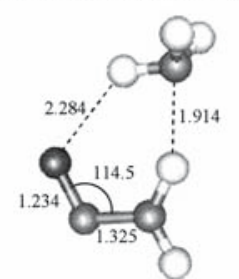

ReaCOM and ProdCOM

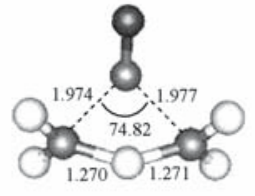

TS

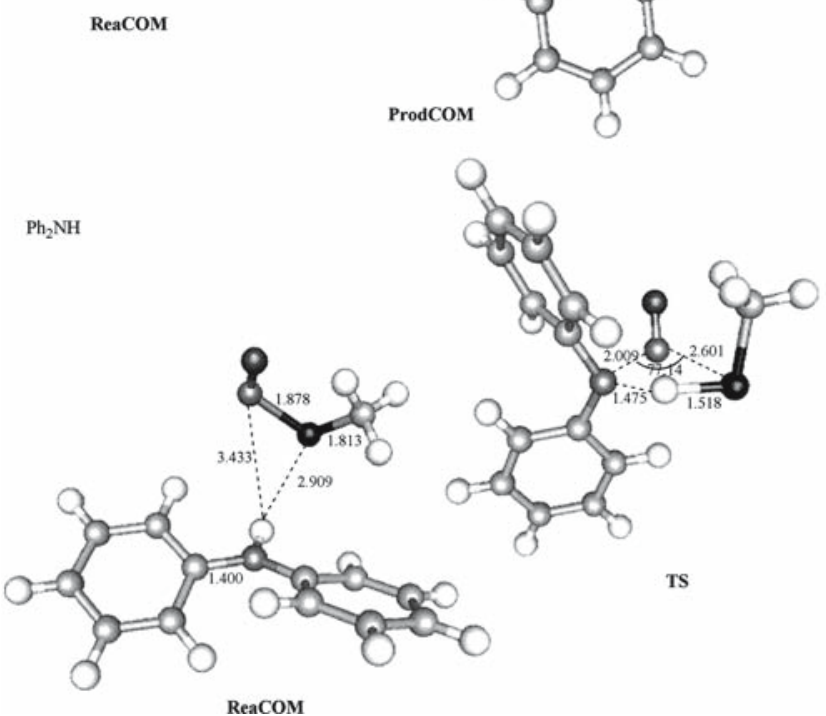

Fig. 3 The optimized geometries of various complexes and TSs of transnitrosation reactions (The bond length in $\AA$, the bond angle in ${ }^{\circ}$, the color of the atom decreases from black to white according to atomic number)

[41]. Accordingly, they concluded that a study of the potential surface of $\mathrm{SO}_{3}$ with two or more water was necessary in order to obtain a complete picture. Figure 4 depicts the opti- mized geometries of ReaCOMs, TSs and ProdCOMs containing one extra water or ammonia. Clearly, the bond length of $\mathrm{N}-\mathrm{H}$ in TS, which is ready to break, is influenced more upon 


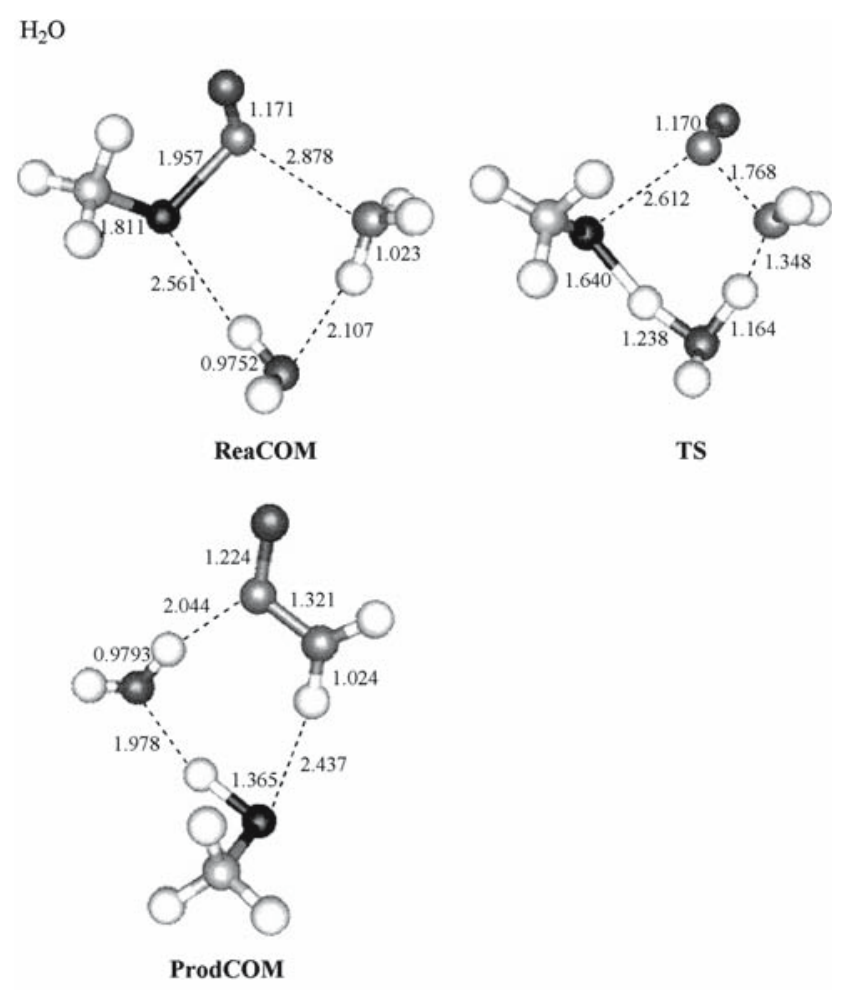

Table 6 The change of activation energies, $\% \mathrm{~N}-\mathrm{H}$ and $\% \mathrm{~N}-\mathrm{S}$ when one extra water or ammonia molecule is added to the transnitrosation reaction cis-MeSNO $+\mathrm{NH}_{3} \rightarrow \mathrm{H}_{2} \mathrm{NNO}+\mathrm{MeSH}$

\begin{tabular}{lcc}
\hline & $\mathrm{NH}_{3}$ & $H_{2} \mathrm{O}$ \\
\hline$\Delta E_{\mathrm{a}}^{\mathrm{a}}$ & 4.7 & 4.5 \\
$\Delta E_{\mathrm{a}}^{\prime \mathrm{b}}$ & 0.2 & 0.7 \\
$\Delta(\% \mathrm{~N}-\mathrm{H})^{\mathrm{c}}$ & 22.33 & 3.427 \\
$\Delta(\% \mathrm{~N}-\mathrm{S})^{\mathrm{d}}$ & -6.694 & -8.613 \\
\hline
\end{tabular}

${ }^{\mathrm{a}} \Delta E_{\mathrm{a}}=E_{\mathrm{a}}$ (adding one extra water or ammonia) $-E_{\mathrm{a}}$

b $\Delta E_{\mathrm{a}}^{\prime}=E_{\mathrm{a}}^{\prime}$ (adding one extra water or ammonia) $-E_{\mathrm{a}}^{\prime}$

c $\Delta(\% \mathrm{~N}-\mathrm{H})=\% \mathrm{~N}-\mathrm{H}$ (adding one extra water or ammonia) -

$\% \mathrm{~N}-\mathrm{H}, \% \mathrm{~N}-\mathrm{H}$ are defined in (Eq. 3)

${ }^{\mathrm{d}} \Delta(\% \mathrm{~N}-\mathrm{S})=\% \mathrm{~N}-\mathrm{S}$ (adding one extra water or ammonia) $-\% \mathrm{~N}-\mathrm{S}$, $\% \mathrm{~N}-\mathrm{S}$ are defined in (Eq. 4)

slightly gains the net catalytic effect on the transnitrosation reaction between cis-MeSNO and $\mathrm{NH}_{3}$, the result of which seems to be in agreement with the previous Schlegel's result [15]. Thus, it is believed that the bulk-water catalyzed transnitrosation reactions in the physiological conditions should be more sophisticated. Nevertheless, as shown by a larger reduction of the activation energy (see Table 6), ammonia has a stronger catalytic effect than water, the result of which may be due to the fact that the basicity of $\mathrm{NH}_{3}$ is stronger than that of $\mathrm{H}_{2} \mathrm{O}$.

\section{Conclusion}

To sum up, according to the results presented in this study, the $\mathrm{SN}$ or NS transnitrosation reaction is more favorable via an $\mathrm{S}_{N}$ 2-like pathway. The stability is in the order $\mathrm{H}_{2} \mathrm{NNO}>$ cis-MeHNNO $>$ trans-MeHNNO $>\mathrm{Me}_{2} \mathrm{NNO}>$ trans$\mathrm{PhHNNO}>$ cis-PhHNNO $>$ cis-MeSNO $>\mathrm{Ph}_{2} \mathrm{NNO}>$ $\mathrm{N}$-methylenenitrous amide. Compared to cis-MeSNO, $\mathrm{Ph}_{2} \mathrm{NNO}$ and $\mathrm{N}$-methylenenitrous amide are good candidates as NO donors, in which $N$-methylenenitrous amide is expected to be better than $\mathrm{Ph}_{2} \mathrm{NNO}$ available currently. It is also worth note that the dihedral angle $\angle \mathrm{C}-\mathrm{N}-\mathrm{N}-\mathrm{O}$ in e.g. $\mathrm{N}$-methylenenitrous amide is calculated to be $84.00^{\circ}$, indicating that $\mathrm{H}_{2} \mathrm{C}=\mathrm{N}$ is nearly perpendicular to NO. This result may be due to the fact that the lone pair of nitrogen atom on the fragment $\mathrm{H}_{2} \mathrm{CN}$ must be a $\pi$-type, not a $\sigma$-type, to induce a mesomeric effect with $\pi^{*} \mathrm{~N}-\mathrm{O}$ of the NO group. Clearly, the bond length of $\mathrm{N}-\mathrm{H}$ in TS is influenced more with the addition of ammonia (or water) than that of $\mathrm{N}-\mathrm{S}$. Although the effect is not significant, the water or ammonia molecule shows catalytic effect on the transnitrosation reaction between cis-MeSNO and $\mathrm{NH}_{3}$. All barriers and endothermicities of the transnitrosation reactions are decreased and the values of $\% \mathrm{~N}-\mathrm{H}(\% \mathrm{~N}-\mathrm{S})$ are decreased (increased) if we further consider the solvent effect of water. The results 
imply that bulk water may have more subtle effects on the transnitrosation reaction.

Acknowledgements We are grateful to the National Center for HighPerformance Computing of Taiwan for allowing us generous amounts of computing time. We also thank the National Science Council for financial support.

\section{References}

1. Ignarro LJ (1989) Circ Res 65:1

2. Osanai T, Fujiwara N, Saitoh M, Sasaki S, Tomita H, Nakamura M, Osawa H, Yamabe H, Okumura K (2002) Blood Purif 20:466

3. Ignarro LJ, Buga GM, Word KS, Byrns RE, Chaudhuri G (1987) Proc Natl Acad Sci USA 84:9265

4. Furchgott RF, Zawadzki JV (1980) Nature 288:373

5. Pfeiffer S, Mayer B, Hemmens B (1999) Angew Chem Int Ed 38:1714

6. Fujimori K, Nakajima T (2000) Rev Heteratom Chem 22:181

7. Williams DLH (1999) Acc Chem Res 32:869

8. Feldman PL, Griffith OW, Stuehr DJ (1993) Chem Eng News Dec 20:26

9. Lü JM, Wittbrodt JM, Wang K, Wen Z, Schlegel BH, Wang PG, Cheng JP (2001) J Am Chem Soc 123:2903

10. Al-Sa’Doni H, Ferro A (2000) Clin Sci 98:507

11. de Belder AJ, MacAllistr R, Radomski MW, Moncada S, Valence PJ (1994) Cardiovasc Res 28:691

12. Bryan NS, Rassaf T, Maloney RE, Rodriguez CM, Saijo F, Rodriguez JR, Feelisch M (2004) Proc Natl Acad Sci USA 101:4308

13. Turjanski AG, Leonik F, Estrin DA, Rosenstein RE, Doctorovich F (2000) J Am Chem Soc 122:10468

14. Sonnenschein K, de Groot H, Kirsch M (2004) J Biol Chem 279:45433

15. Li J, Wang GP, Schlegel HB (2006) Org Biomol Chem 4:1352

16. Yanagimoto $\mathrm{T}$, Toyota $\mathrm{T}$, Matsuki $\mathrm{N}$, Makino $\mathrm{Y}$, Uchiyama $\mathrm{S}$, Ohwada T (2007) J Am Chem Soc 129:736

17. Lai C-H, Li EY, Chou P-T (2007) Theor Chem Acc 117:145

18. Bharatam PV and Amita (2002) Tetrahedron Lett 43:8289

19. Frisch MJ, Trucks GW, Schlegel HB, Scuseria GE, Robb MA, Cheeseman JR, Montgomery JA, Vreyen JrT, Kudin KN, Burant JC, Millam JM, Iyengar SS, Tomasi J, Barone V, Mennucci B, Cossi M, Scalmani G, Rega N, Petersson GA, Nakatsuji H, Hada M, Ehara M, Toyota K, Fukuda R, Hasegawa J, Ishida M, Nakajima T, Honda Y, Kitao O, Nakai H, Klene M, Li X, Knox JE, Hratchian HP,
Cross JB, Adamo C, Jaramillo J, Gomperts R, Stratmann RE, Yazyev O, Austin AJ, Cammi R, Pomelli C, Octhterski JW, Ayala PY, Morokuma K, Voth GA, Salvador P, Dannenberg JJ, Zakrzewski VG, Dapprich S, Daniels AD, Strain MC, Farkas O, Malick DK, Rabuck AD, Raghavachari K, Foresman JB, Ortiz JV, Cui Q, Baboul AG, Clifford S, Cioslowski J, Stefanov BB, Liu G, Liashenko A, Piskorz P, Komaromi I, Martin RL, Fox DJ, Keith T, Al-Laham MA, Peng CY, Nanayakkara A, Challacombe M, Gill PMW, Johnson B, Chen W, Wong MW, Gonzalez C and Pople JA (2004) Gaussian 03, Revision C.02 Gaussian, Inc., Pittsburgh PA

20. Head-Gordon M, Pople JA, Frisch MJ (1988) Chem Phys Lett 153:503

21. Becke AD (1993) J Chem Phys 98:5648

22. Adamo C, Barone V (1998) J Chem Phys 108:664

23. Lynch BJ, Fast PL, Harris M, Truhlar DG (2000) J Phys Chem A 104:4811

24. Handy NC, Pople JA, Head-Gordon M, Raghavachari K, Trucks GW (1989) Chem Phys Lett 164:185

25. Carpenter JE, Weinhold F (1988) Theochem 169:41

26. Miertus S, Scrocco E, Tomasi J (1981) Chem Phys 55: 117-129

27. Al-Mustafa AH, Sies H, Stahl W (2001) Toxicology 163:127

28. Lisa A, Peterson LA, Wagener T, Sies H, Stahl W (2007) Chem Res Toxicol 20:721

29. Adam C, Garcia-Rio L, Leis JR, Ribeiro L (2005) J Org Chem 70:6353

30. Bartberger MD, Houk KN, Powell SC, Mannion JD, Lo KY, Stamler JS, Toone EJ (2000) J Am Chem Soc 122:5889

31. Fu Y, Mou Y, Lin B-L, Liu L, Guo Q-X (2002) J Phys Chem A $106: 12386$

32. Baciu C, Gauld JW (2003) J Phys Chem A 107:9946

33. West R (2004) Science 1724

34. Zhu XQ, He JQ, Li Q, Xian M, Lu J, Cheng JP (2000) J Org Chem 65:6729

35. Cheng JP, Xian M, Wang K, Zhu X, Yin Z, Wang PG (1998) J Am Chem Soc 120:10266

36. Bulter AR, Williams DLH (1993) Chem Soc Rev 22:233

37. Lü JM, Wittbrodt JM, Wang K, Wen Z, Schlegel BH, Wang PG, Cheng JP (2001) J Am Chem Soc 123:2903

38. Curtiss LA, Raghavachari K, Redfern PC, Rassolov V, Pople JA (1998) J Chem Phys 109:7764

39. Lai C-H, Chou P-T (2007) J Mol Model ASAP

40. Houk KN, Hietbrink BN, Bartberger MD, McCarren PR, Cho BY, Voyksner RD, Stamler JS, Toone EJ (2003) J Am Chem Soc 125:6972

41. Chen TS, Plummer PLM (1985) J Phys Chem 89:3689 